\title{
CHARACTERISTICS OF FLOW AND SCOUR UNDER THE EFFEC CURVED STEEL ROUGHNESS ELEMENTS
}

Amany A. Habib, Mohamed A. Nassar

\begin{abstract}
Flow and scour characteristics are investigated experimentally on a modified roughened bed. The water su is recorded at different sections. The paper investigated the effects of using curved steel sheets as roughn for strip and staggered arrangement, on different flow and scour characteristics. It was found that the apri staggered roughness length increases the relative energy loss by $17 \%$, reduces the relative jump length b decreases the relative jump depth by $15.5 \%$ compared to the smooth bed. Generally, the experiments indic case of staggered roughness elements gives the best relative jump characteristics. Moreover, it plays an in to control the scour downstream the basin. The derived theoretical equations for relative depth and the rel loss give an acceptable agreement with the experimental data. Prediction equations were developed using linear regression (MLR) to model the hydraulic jump characteristics. A good agreement was obtained betw predicted and the measured values. Finally, this study yielded conclusions which can be recommended in $t$ procedure and practical applications
\end{abstract}

